Article

\title{
Bioactivity-Guided Purification of Novel Herbal Antioxidant and Anti-NO Compounds from Euonymus laxiflorus Champ.
}

\author{
Van Bon Nguyen $1, * \mathbb{(}$, San-Lang Wang ${ }^{2,3, * \mathbb{D}}$, Anh Dzung Nguyen ${ }^{4, *}$, Zhi-Hu Lin ${ }^{5}$, \\ Chien Thang Doan ${ }^{2,6}{ }^{\infty}$, Thi Ngoc Tran ${ }^{2,6}$, Hung Tse Huang 7,8 and Yao-Haur Kuo ${ }^{5,9,10, *}$ \\ 1 Institute of Research and Development, Duy Tan University, Da Nang 550000, Vietnam \\ 2 Department of Chemistry, Tamkang University, New Taipei City 25137, Taiwan; \\ doanthng@gmail.com (C.T.D.); tranngoctnu@gmail.com (T.N.T.) \\ 3 Life Science Development Center, Tamkang University, New Taipei City 25137, Taiwan \\ 4 Institute of Biotechnology and Environment, Tay Nguyen University, Buon Ma Thuot 630000, Vietnam \\ 5 Division of Chinese Materia Medica Development, National Research Institute of Chinese Medicine, \\ Taipei 11221, Taiwan; tiger77749@gmail.com \\ 6 Department of Science and Technology, Tay Nguyen University, Buon Ma Thuot 630000, Vietnam \\ 7 Division of Chinese Materia Medica Development, National Research Institute of Chinese Medicine, \\ Taipei 11221, Taiwan; kk49310953@nricm.edu.tw \\ 8 Department of Biochemical Science and Technology, National Taiwan University, Taipei 106, Taiwan \\ 9 Graduate Institute of Integrated Medicine, College of Chinese Medicine, China Medical University, \\ Taichung 40402, Taiwan \\ 10 Ph.D. Program for Clinical Drug Development of Chinese Herbal Medicine, College of Pharmacy, \\ Taipei Medical University, Taipei 11031, Taiwan \\ * Correspondence: bondhtn@gmail.com (V.B.N.); sabulo@mail.tku.edu.tw (S.-L.W.); \\ nadzungtaynguyenuni@yahoo.com.vn (A.D.N.); kuoyh@nricm.edu.tw (Y.-H.K.); \\ Tel.: +84-098-455-8214 (V.B.N.)
}

Received: 13 November 2018; Accepted: 24 December 2018; Published: 30 December 2018

\begin{abstract}
Euonymus laxiflorus Champ., a medicinal herb collected in Vietnam, has been reported to show several potent bioactivities, including anti-NO, enzyme inhibition, hypoglycemic and antidiabetic effects. Recently, the antioxidant activity of Euonymus laxiflorus Champ. trunk bark (ELCTB) has also been reported. However, the active antioxidant and anti-NO constituents existing in ELCTB have not been reported in the literature. The objective of this study was to purify the active antioxidants from ELCTB and investigate the anti-NO effect of the major constituents. Twenty-two phenolics isolated from ELCTB, including 12 compounds newly isolated in this study (1-12) and 10 constituents obtained from our previous work, were evaluated for their antioxidant activity. Of these, 12 compounds $(\mathbf{4 - 6}, \mathbf{9}, \mathbf{1 3}-\mathbf{1 5}, \mathbf{1 8}-\mathbf{2 2})$ showed a potent antioxidant capacity (FRS50 = $7.8-58.11 \mu \mathrm{g} / \mathrm{mL}$ ), in comparison to $\alpha$-tocopherol (FRS50 $=23 \mu \mathrm{g} / \mathrm{mL}$ ). In the anti-NO activity tests, Walterolactone A (1a) and B (1b) $\beta$-D-glucopyranoside (13) demonstrated the most effective and comparable activity to that of quercetin with max inhibition and $\mathrm{IC}_{50}$ values of $100 \%, 1.3 \mu \mathrm{g} / \mathrm{mL}$, and $100 \%, 1.21 \mu \mathrm{g} / \mathrm{mL}$, respectively. The crude extract and its major compounds showed no cytotoxicity on normal cells. Notably, three constituents $(\mathbf{9}, \mathbf{1 1}$, and 12) were identified as new compounds, another three constituents, including 1,7 , and 8 , were found to be new natural products, constituents 9 and 13 were determined to be new antioxidants, and compound 13 was reported to have novel potent anti-NO activity for the first time. The results of this study contribute to the enrichment of new natural products and compounds, as well as the novel biological activity of constituents isolated from Euonymus laxiflorus Champ. The current study also indicates ELCTB as a rich natural source of active phenolics. It is suggested that ELCTB could be developed as a health food with promising antioxidant and anti-NO effects, as well as other beneficial biological activities.
\end{abstract}


Keywords: antioxidants; anti-NO; Euonymus laxiflorus; Walterolactone A (1a) and B (1b) $\beta$-D-glucopyranoside; bioactive compounds

\section{Introduction}

Living organisms are negatively affected by free radicals in areas such as DNA, proteins, and lipid damage, and as such, they may cause various diseases [1]. These unexpected effects can be reduced and prevented by antioxidant compounds which can be synthesized or obtained from natural resources. However, synthetic antioxidants can cause carcinogenesis and liver damage [2]. Thus, the discovery of abundant and natural antioxidants is still needed. Antioxidants may be obtained from several natural sources, including higher plants [3-5], microbial fermentation [6,7], and marine products $[8,9]$. Of these, herbal antioxidants have been given much exploration in recent years [10].

Vietnam is a tropical country and is considered the sixteenth most biodiverse region in the world. It possesses around 10,000 herbal species, of which 4000 have been used as medicinal plants [11]. Therefore, there has been increased interest in the seeking and purification of bioactive constituents from Vietnamese herbs in recent years [4,5,10,12-17]. Numerous herbs showing enzymic inhibitory, hypoglycemic, and antidiabetic effects have been investigated [4,5,12-17]. The antioxidant and anticancer effects of the herbs collected in this biodiverse region have also been reported in several works $[4,5,10]$. However, only a few herbs possessing anti-NO properties have been reported, and there are also few studies working on the isolation and identification of active compounds (antioxidant and anti-NO constituents). Thus, the investigation of natural products processing beneficial properties from the herbs of this biodiverse area has been received with great attention.

Euonymus laxiflorus Champ.-A medicinal herb, is wildly distributed in Vietnam $[12,17]$ and some other Asian countries, including China, Cambodia, India, and Myanmar [18]. This medicinal herbal species has been recognized as a rich source of bioactive natural products and has been extensively investigated to reclaim its potent antidiabetic properties via enzymic inhibition and animal tests $[4,12,13]$. These previous studies revealed that Euonymus laxiflorus Champ. shows potency for $\alpha$-amylase inhibition [13], $\alpha$-glucosidase inhibition [12], as well as a significant effect on the reduction of blood glucose in diabetic rats [4]. Recently, novel potent antidiabetic compounds have been isolated and identified from Euonymus laxiflorus trunk bark extract [14,17]. Of these, poly condensed tannin, a major antidiabetic compound, has demonstrated a significant effect on reducing plasma glucose in ICR mice [17]. Some constituents isolated from the leaves of this plant have shown anti-nitric oxide and antioxidant effects [19]. However, little data on the antioxidant properties of this herbal extract exists beyond the previous reports [4], and no compounds isolated from the trunk bark extract of this herb have been reported for the evaluation of antioxidant and anti-NO capacities.

As a part of the objective to indicate scientific proof for the development of Euonymus laxiflorus Champ. as potent functional food or drug, this study investigated the bioactivity of this herb to isolate and identify its chemical constituents. In the current study, the potent antioxidant capacity of Euonymus laxiflorus Champ. was reclaimed, and the isolation and identification of its active compounds, as well as an evaluation of its antioxidant and anti-NO activities, were also reported. The results of this study contributed to the enrichment of new natural products and novel compounds, as well as the new biological effects of the constituents isolated from Euonymus laxiflorus.

\section{Results and Discussion}

\subsection{Reclamation of Euonymus laxiflorus Champ. Extracts as a Potential Source of Beneficial Bioactive Properties without Toxicity}

The methanol extract of Euonymus laxiflorus Champ. trunk bark (ELCTB) was evaluated for its DPPH radical scavenging activity (antioxidant activity), and the results are illustrated in Figure 1 
(\%) and Table 1 (FRS50). ELCTB showed potent antioxidant activity with great max activity (\%) and low FRS50 values of $97 \%$ and $20.2 \mu \mathrm{g} / \mathrm{mL}$, respectively. The antioxidant activity of $\alpha$-tocopherol, a commercial antioxidant compound, was also tested for comparison and showed approximately equal activity, with max activity (\%) and low FRS50 values of $99 \%$ and $24.4 \mu \mathrm{g} / \mathrm{mL}$, respectively. In the comparison, Euonymus laxiflorus Champ. also showed comparable or higher antioxidant activity than those of some recently-reported medicinal extracts collected in the central highlands of Vietnam (Table 1).

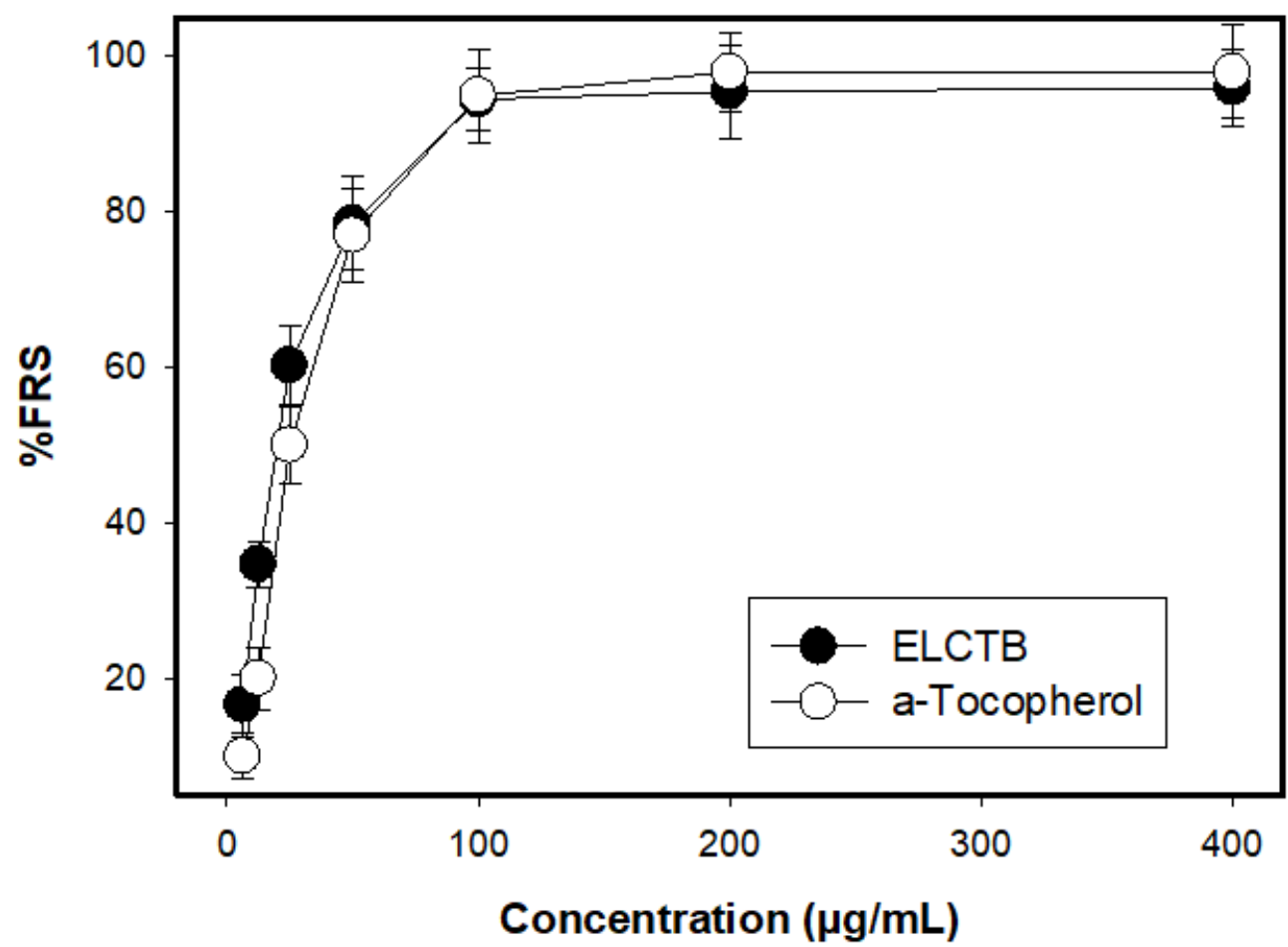

Figure 1. Antioxidant activity (\%) of the methanol extract of Euonymus laxiflorus Champ. trunk bark (ELCTB) and $\alpha$-tocopherol. The methanol extract of ELCTB and $\alpha$-tocopherol were tested at their concentration range of 3.125-400 $\mu \mathrm{g} / \mathrm{mL}$. FRS: Free radical scavenging

Table 1. Antioxidant activity of other $\mathrm{MeOH}$ extracts of medicinal plants collected in Dak Lak.

\begin{tabular}{cccc}
\hline Scientific Name of Medicinal Plants & Part Used & FRS50 $(\boldsymbol{\mu g} / \mathbf{m L})$ & Ref. \\
\hline Euonymus laxiflorus Champ. & Trunk bark & $20.2 \pm 0.45$ & This study \\
$\alpha$-Tocopherol * & & $24.4 \pm 0.87$ & Nguyen et al., 2016 [5] \\
Terminalia alata & Trunk bark & $240 \pm 20$ & Nguyen et al., 2016 [5] \\
T. bellirica & Trunk bark & $1020 \pm 20$ & Nguyen et al., 2016 [5] \\
T. corticosa & Trunk bark & $250 \pm 0.00$ & Nguyen et al., 2016 [5] \\
L-ascorbic acid * & & $240 \pm 0.00$ & Nguyen, Q.V. 2017 [10] \\
T. nigrovenulosa & Bark extract & $273 \pm 3$ & Nguyen, Q.V. 2017 [10] \\
T. nigrovenulosa & Leaves extract & $408 \pm 6$ &
\end{tabular}

${ }^{*}$ Commercial antioxidant compounds.

The trunk bark of Euonymus laxiflorus Champ. has been reported to possess promising $\alpha$-glucosidase inhibitory and $\alpha$-amylase inhibitory activities [12,13] and significant effects on the reduction of plasma glucose in normal and diabetic mice $[4,17]$. The anti-NO activity of the extract from the leaves of this herb was investigated by Liu et al. (2014) [19]. In addition, Euonymus laxiflorus has been proved to be non-toxic via animal models in previous reports [4]. In this study, ELCTB was found to show potential antioxidant activity, therefore an investigation was conducted to isolate and identify its active compounds, which were subsequently evaluated for their beneficial bioactivities. 
2.2. Selective Solvent Extraction for Max Antioxidant Productivity from Euonymus laxiflorus Champ. Extracts and Purification of Active Compounds

Five solvents, including water, butanol, ethanol, methanol, and ethyl acetate, were used to extract Euonymus laxiflorus Champ. trunk bark (ELCTB), and then all extracts were evaluated for antioxidant activity. As shown in Figure 2A, the ELCTB extracted by methanol demonstrated the highest activity due to its smallest FRS50 value of $20 \mu \mathrm{g} / \mathrm{mL}$. Therefore, the methanol extract was chosen for the next step of purification.

A

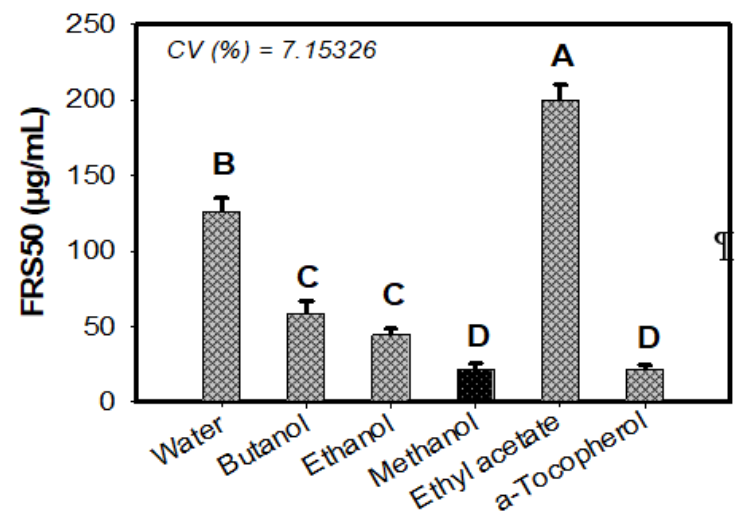

Solvents for extraction

\section{C}

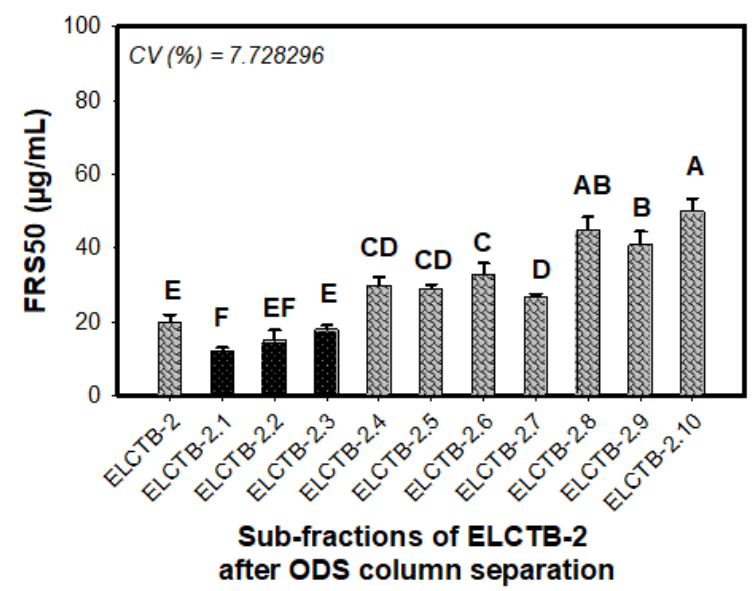

B

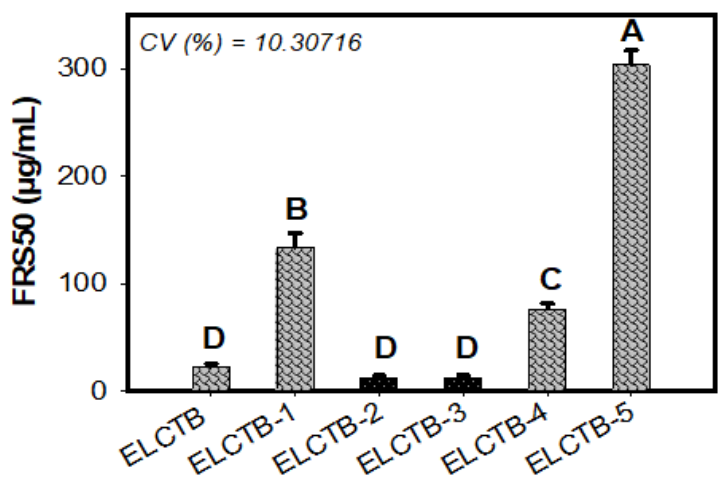

Fractions of ELCTB extract after Diaion column separation

\section{D}

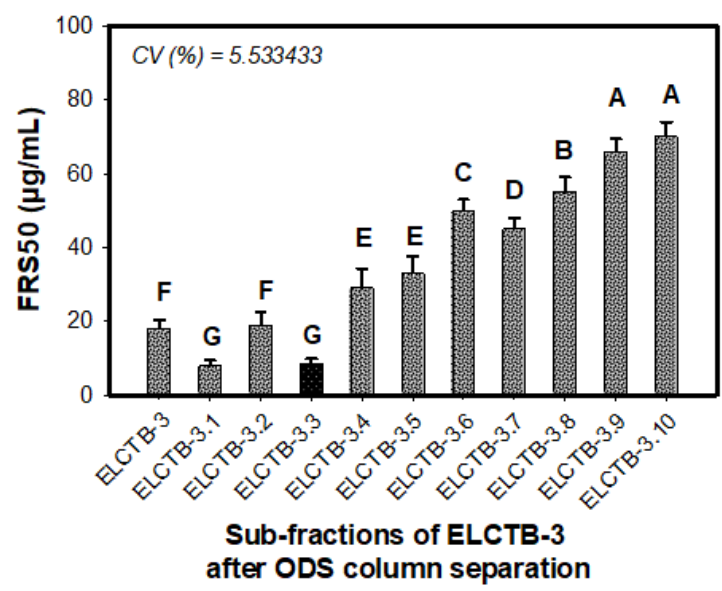

Figure 2. Antioxidant activity of the Euonymus laxiflorus Champ. trunk bark (ELCTB) extracted using different solvents: (A) ELCTB and its fractions after Diaion column; (B) fraction ELCTB-2 and its sub-fractions; (C) fraction ELCTB-3 and its sub-fractions; (D) after silica columns. The means of FRS50 with different letters in the same figure were significantly different based on Duncan's multiple range test at alpha $=0.01$.

ELCTB was primary separated via a Diaion column to obtain the five fractions of ELCTB-1 (20.97 g), ELCTB-2 (9.12 g), ELCTB-3 (4.67 g), ELCTB-4 (1.46 g), and ELCTB-5 (1.63 g) through successive eluting with distilled water, $40 \% \mathrm{MeOH}, 70 \% \mathrm{MeOH}, 100 \% \mathrm{MeOH}$, and 100\% ethyl acetate, respectively. The antioxidant activity of ELCTB and these separated fractions were tested as shown in Figure 2B. Two fractions (ELCTB-2, and ELCTB-3) showed the smallest FRS50 values of 12.25 and $12.42 \mu \mathrm{g} / \mathrm{mL}$, respectively, and as such possessed the highest activity. These potent fractions were further purified via ODS columns to obtain a total of 20 sub-fractions. Of these, three sub-fractions, ELCTB-2.1, ELCTB-2.2, and ELCTB-2.3 were separated from ELCTB-2, and one sub-fraction, ELCTB-3.3, was separated from ELCTB-3. These sub-fractions possessed significant activity, and as such were 
purified to isolate their constituents. The utilization of preparative HPLC resulted in the isolation of 12 (1-12) compounds from these four active sub-fractions. The isolation process is briefly presented in Figure 3.

\section{ELCTB - Crude extract sample(40g)}

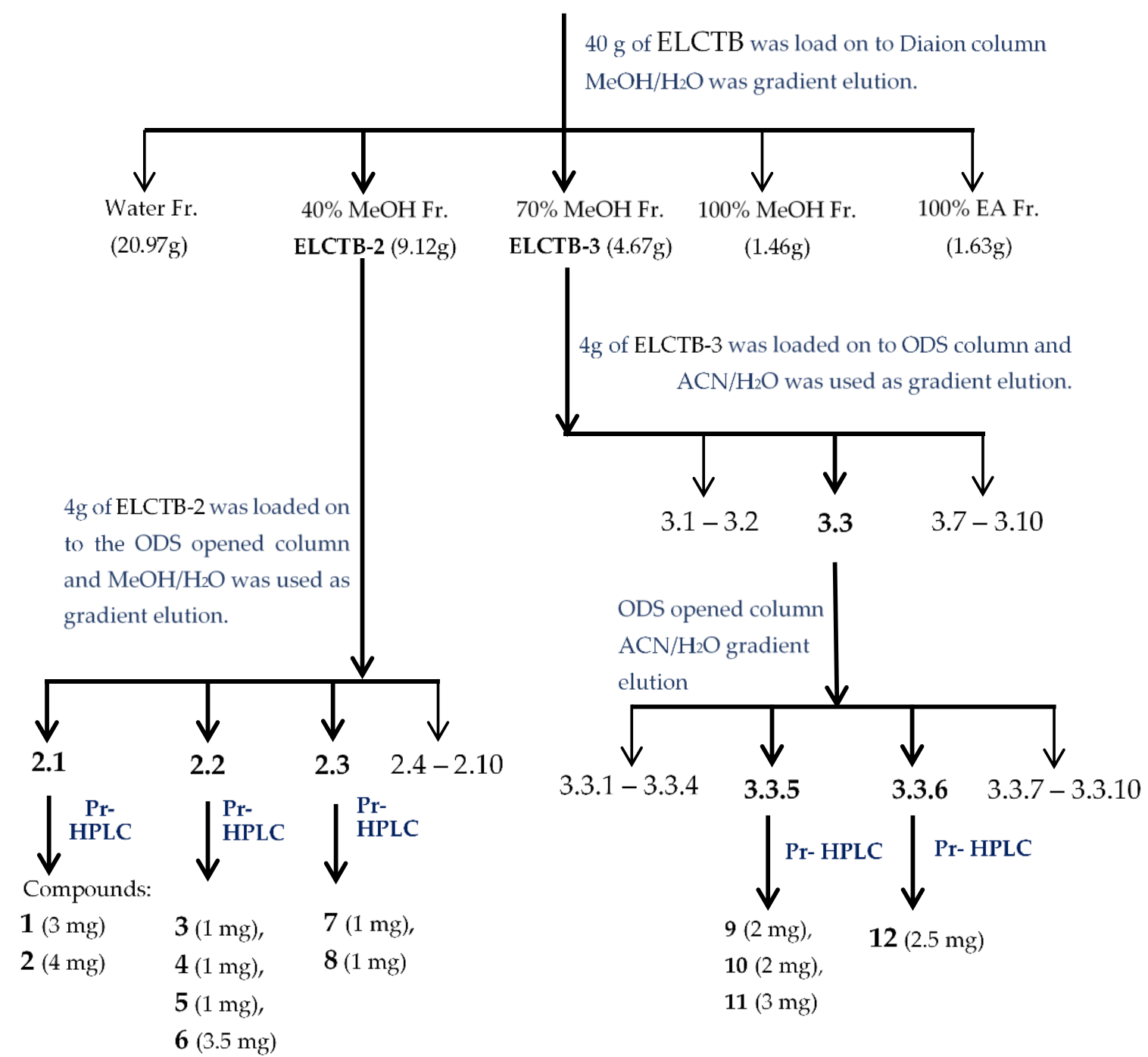

Figure 3. Isolation chart of the active constituents from Euonymus laxiflorus Champ. trunk bark (ELCTB) extract. EA: acetyl acetate; $\mathrm{MeOH}$ : methanol; Pr-HPLC: preparative high-performance liquid chromatography; ACN: acetonitrile; ODS: octadecylsilane.

\subsection{Identification of Isolated Constituents from Euonymus laxiflorus Champ.}

The 12 constituents newly isolated from ELCTB were identified as Umbelactone (1) [20], Walterolactone (2) [21], Phenylalanine (3) [22], 2-methoxy-4-hydroxyphenol-1-O- $\beta$-D-glucopyranoside (4) [23], 1- $\beta$-D-glucopyranosyloxy-3,5-dimethoxy-4-hydroxybenzene (5) [24], (-)-3,4-(Dihydroxybenzoic acid (6) [25], 2-benzoyl myo-inositol (7) [26], 1-O-Benzoyl-myo-inositol (8) [27], walterolactone A/B 6-O-gallate- $\beta$-D-glucopyranoside (9), Roseoside (6S, 9S) (10) [28], (3R*,6R*)-tetrahydro-6-ethenyl-2,2,6trimethyl-2H-pyran 3-O- $\alpha$-L-arabinopyranosyl ( $1 \rightarrow 3)$ - $\beta$-D-glucuronopyranosyl (11), and 7-Hydroxy6,7-dihydro-cis/trans- geraniate, 3-O- $\alpha$-L-arabinopyranosyl ( $1 \rightarrow 6)-\beta$-D-glucopyranosyl (12).

Based on the literature review, three compounds, Umbelactone (1), 2-benzoyl myo-inositol (7), and 1-O-Benzoyl-myo-inositol (8) were found to be new natural products. Notably, walterolactone A/B 6-O-gallate- $\beta$-D-pyranoglucoside (9), $\left(3 R^{*}, 6 R^{*}\right)$-tetrahydro-6-ethenyl-2,2,6-trimethyl-2H-pyran 
3-O- $\alpha$-L-arabinopyranosyl (1 $\rightarrow 3$ )- $\beta$-D-glucuronopyranosyl (11), and 7-Hydroxy-6,7-dihydro-cis/transgeraniumsaeure 3-O- $\alpha$-L-arabinopyranosyl $(1 \rightarrow 6)-\beta$-D-glucopyranosyl (12) were identified as new compounds. Their characteristics and NMR data were recorded as shown below. The results of this study contributed to the enrichment of new natural products, as well as the enrichment of the novel constituents of Euonymus laxiflorus Champ.

Walterolactone $A / B$ 6-O-gallate- $\beta$-D-pyranoglucoside (9) was obtained as a white amorphous powder. ${ }^{1} \mathrm{H}-\mathrm{NMR}$ data $\left(600 \mathrm{MHz}, \mathrm{MeOH}-d_{4}, \delta_{\mathrm{H}} \mathrm{ppm}\right): 7.05(\mathrm{~s}, 2 \mathrm{H}), 5.81(\mathrm{brs}), 4.58(\mathrm{dd}, J=12.0,2.4 \mathrm{~Hz}), 4.54$ $(\mathrm{dd}, J=12.6,3.0 \mathrm{~Hz}), 4.44(\mathrm{~d}, J=7.8 \mathrm{~Hz}), 4.39(\mathrm{dd}, J=12.6,3.0 \mathrm{~Hz}), 4.22(\mathrm{t}, J=3.0 \mathrm{~Hz}), 4.10(\mathrm{dd}$, $J=12.0,6.0 \mathrm{~Hz}), 3.60(\mathrm{~m}), 3.4(\mathrm{~m}, 2 \mathrm{H}), 3.2(\mathrm{~m}), 2.14(\mathrm{brs}) .{ }^{13} \mathrm{C}-\mathrm{NMR}$ data $\left(150 \mathrm{MHz}, \mathrm{MeOH}-d_{4}, \delta_{\mathrm{C}}\right.$ ppm): 168.2, 166.0, 158.2, 146.5, 140.0, 121.4, 118.9, 110.1, 103.3, 77.8, 75.6, 74.7, 71.7, 71.6, 70.6, 64.6, 20.5. The chemical structure and the key correlations of HMBC and COSY for this compound are shown in Figure 4.

$\left(3 R^{*}, 6 R^{*}\right)$-tetrahydro-6-ethenyl-2,2,6-trimethyl-2H-pyran $\quad 3-O-\alpha$-L-arabinopyranosyl $\quad(1 \rightarrow 3)-\beta$-Dglucuronopyranosyl (11) was obtained as a white amorphous powder. ${ }^{1} \mathrm{H}-\mathrm{NMR}$ data $(600 \mathrm{MHz}$, MeOH- $\left.d_{4}, \delta_{\mathrm{H}} \mathrm{ppm}\right): 5.95(\mathrm{dd}, J=18.0,11.2 \mathrm{~Hz}), 5.05(\mathrm{~d}, J=18.0 \mathrm{~Hz}), 4.97(\mathrm{~d}, J=1.8 \mathrm{~Hz}), 4.95(\mathrm{~d}$, $J=11.2 \mathrm{~Hz}), 4.32(\mathrm{~d}, J=7.8 \mathrm{~Hz}), 4.00(\mathrm{dd}, J=11.4,2.4 \mathrm{~Hz}), 3.98(\mathrm{dd}, J=3.0,1.8 \mathrm{~Hz}), 3.96(\mathrm{td}, J=5.4$, $3.0 \mathrm{~Hz}), 3.82(\mathrm{dd}, J=6.0,3.0 \mathrm{~Hz}), 3.74(\mathrm{dd}, J=14.4,3.0 \mathrm{~Hz}), 3.64(\mathrm{dd}, J=14.4,5.4 \mathrm{~Hz}), 3.60(\mathrm{dd}, J=11.4$, $6.0 \mathrm{~Hz}$ ), $3.43(\mathrm{~m}), 3.41$ (overlapped), 3.32 (overlapped), $3.23(\mathrm{dd}, J=9.6,9.0 \mathrm{~Hz}), 3.12(\mathrm{dd}, J=9.0$, $7.8 \mathrm{~Hz}), 2.15(\mathrm{ddd}, J=13.8,3.0,2.4 \mathrm{~Hz}), 1.97(\mathrm{dq}, J=13.2,4.2 \mathrm{~Hz}), 1.75(\mathrm{qd}, J=13.2,3.6 \mathrm{~Hz}), 1.60(\mathrm{td}$, $J=13.8,2.4 \mathrm{~Hz}), 1.25(\mathrm{~s}, 3 \mathrm{H}), 1.18(\mathrm{~s}, 3 \mathrm{H}), 1.08(\mathrm{~s}, 3 \mathrm{H}) .{ }^{13} \mathrm{C}-\mathrm{NMR}$ data $\left(150 \mathrm{MHz}, \mathrm{MeOH}-d_{4}, \delta_{\mathrm{C}} \mathrm{ppm}\right)$ : $147.4,111.5,109.9,106.3,86.0,85.9,83.2,79.0,78.1,77.1,76.6,75.3,74.9,72.0,68.2,63.1,33.6,32.2,30.0$, 25.8, 22.0. The chemical structure and key correlations of HMBC and COSY for this compound are shown in Figure 4.

7-Hydroxy-6,7-dihydro-cis/trans-geraniate, $3-O-\alpha$-L-arabinopyranosyl $(1 \rightarrow 6)-\beta$-D-glucopyranosyl (12). ${ }^{1} \mathrm{H}-\mathrm{NMR}$ data $\left(400 \mathrm{MHz}, \mathrm{MeOH}-d_{4}, \delta_{\mathrm{H}} \mathrm{ppm}\right): 5.76(\mathrm{brs}), 5.47(\mathrm{~d}, J=8.0 \mathrm{~Hz}), 4.90(\mathrm{brs}), 3.99$ (dd, $J=11.4,2.4 \mathrm{~Hz}), 3.98(\mathrm{~m}), 3.96(\mathrm{~m}), 3.80(\mathrm{~m}), 3.74(\mathrm{dd}, J=11.4,3.0 \mathrm{~Hz}), 3.62(\mathrm{dd}, J=11.4,5.4 \mathrm{~Hz}), 3.59$ $(\mathrm{dd}, J=11.4,6.0 \mathrm{~Hz}), 3.57(\mathrm{~m}), 3.42(\mathrm{t}, J=8.8 \mathrm{~Hz}), 3.34(\mathrm{~m}, 2 \mathrm{H}), 2.20(\mathrm{t}, J=6.8 \mathrm{~Hz}), 2.18(\mathrm{~s}, 3 \mathrm{H}), 1.57$ $(\mathrm{m}, 2 \mathrm{H}), 1.43(\mathrm{~m}, 2 \mathrm{H}), 1.17(\mathrm{~s}, 6 \mathrm{H}) .{ }^{13} \mathrm{C}-\mathrm{NMR}$ data $\left(100 \mathrm{MHz}, \mathrm{MeOH}-d_{4}, \delta_{\mathrm{C}} \mathrm{ppm}\right): 166.4,164.7,115.9$, $110.0,95.1,85.7,83.2,78.8,78.0,77.5,73.9,71.6,71.2,67.9,63.0,44.0,42.4,29.2,23.2,19.1$. The chemical structure and the key correlations of HMBC and COSY for this compound are shown in Figure 4.

\subsection{Evaluation of Antioxidant Activity of Identified Compounds from ELCBT}

All of the newly identified compounds (1-12) in this study, as well as the ten compounds (13-22) obtained from our previous study [14], including walterolactone A (1a) and B (1b) $\beta$-D-glucopyranoside (13), gallic acid (14), (-)-Gallocatechin (15), 1-(4-hydroxyphenyl)-2,3-dihydroxypropan-1-one 3-O$\beta$-D-glucopyranoside (16), Myo-inositol 1-O-3,3-dimethylacrylate (17), leonuriside (18), (+)-Catechin (19), methyl galloate (20), (-)-Catechin (21), and (3,5-dimethoxy-4-hydroxyphenol)-1-O- $\beta$-D(6'-O-galloyl)-glucopyranoside (22) were evaluated for their antioxidant capacity at a concentration range of $0.5-250 \mu \mathrm{g} / \mathrm{mL}$. The activity was estimated and expressed as FRS50 values and the max activity was recorded at $250 \mu \mathrm{g} / \mathrm{mL}$ (Table 2). Of these 22 tested constituents, 6, 9, 14 and 19-22 demonstrated stronger activity (FRS50 $=7.8-16.77 \mu \mathrm{g} / \mathrm{mL}$, ranked at the $\boldsymbol{e}-f$ level) than that of $\alpha$-tocopherol (FRS50 $=23 \mu \mathrm{g} / \mathrm{mL}$, ranked at the $d$ level); 13 and 18 showed comparable activity (FRS50 $=27.47-28 \mu \mathrm{g} / \mathrm{mL}$, ranked at the $\boldsymbol{e}-\boldsymbol{f}$ level) to that of the positive control, since their FRS50 values were ranked at the same level as $\boldsymbol{c} \boldsymbol{d}-\boldsymbol{d}$; while $\mathbf{4}, \mathbf{5}$, and $\mathbf{1 5}$ had lower activity (FRS50 $=30.73-58.11 \mu \mathrm{g} / \mathrm{mL}$, ranked at the $\boldsymbol{a}-\boldsymbol{c}$ level) than $\alpha$-tocopherol, based on Duncan's multiple range test at alpha $=0.01$. However, these 12 antioxidants all possessed strong max antioxidant activity (92-100\%, ranked at the $a$ level) that was equal to that of $\alpha$-tocopherol (99\%, ranked at the $a$ level); as such they could be identified as potent antioxidant compounds. Compounds 11 and 12 possessed weak activity with max activity of 20-25\%, 
and the other nine constituents showed no activity. The results indicated that ELCBT was a potentially rich source of active antioxidant compounds.<smiles>COc1cc(O[C@@H]2O[C@H](CO)[C@@H](O)[C@H](O)[C@H]2O)cc(OC)c1O</smiles><smiles>O=C(O)c1ccc(O)c(O)c1</smiles><smiles>O=C(O[C@@H]1[C@H](O)[C@@H](O)[C@H](O)[C@@H](O)[C@H]1O)c1ccccc1</smiles><smiles>O=C(O[C@H]1[C@H](O)[C@@H](O)[C@@H](O)[C@H](O)[C@H]1O)c1ccccc1</smiles><smiles>CC1=CC(=O)CC(C)(C)[C@@]1(O)/C=C/[C@@H](C)O[C@@H]1O[C@H](CO)[C@@H](O)[C@H](O)[C@H]1C</smiles>

(a)

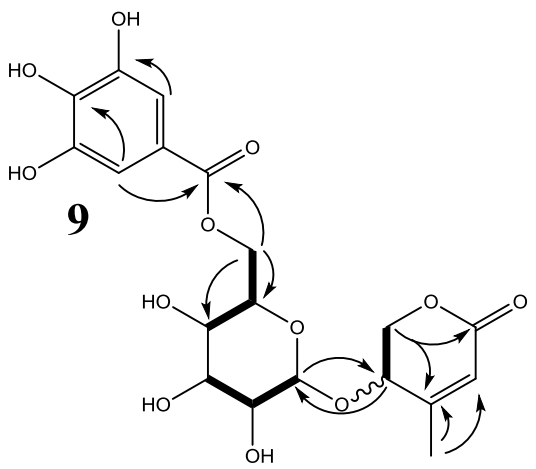

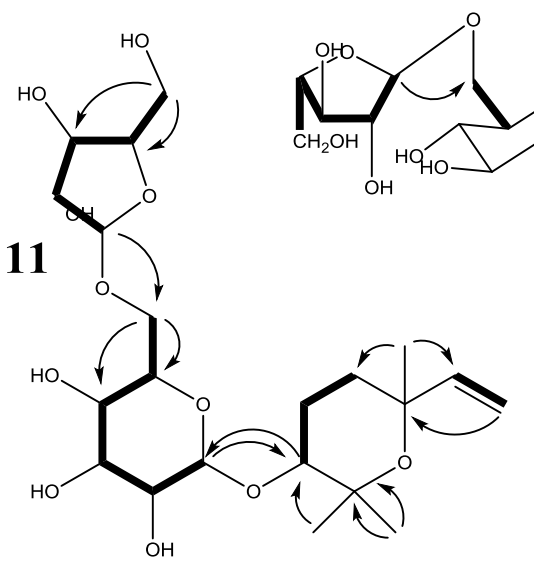

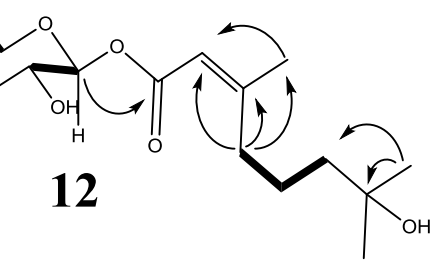

(b)

Figure 4. Chemical structures of isolated compounds from the trunk bark of Euonymus laxiflorus Champ: (a), key correlations of HMBC (heteronuclear multiple bond correlation) and COSY (correlated spectroscopy) of the three new compounds; (b) Umbelactone (1), Walterolactone (2), Phenylalanine (3), 2-methoxy-4-hydroxyphenol-1-O- $\beta$-D-glucopyranoside (4), 1- $\beta$-D-glucopyranosyloxy-3,5-dimethoxy4-hydroxybenzene (5), 3,4-Dihydroxybenzoic acid (6), 2-benzoyl myo-inositol (7), 1-O-Benzoyl-myoinositol (8), walterolactone A/B 6-O-gallate- $\beta$-D-glucopyranoside (9), Roseoside (6S, 9S) (10), $\left(3 R^{*}, 6 R^{*}\right)$-tetrahydro-6-ethenyl-2,2,6-trimethyl-2H-pyran 3-O- $\alpha$-L-arabinopyranosyl $(1 \rightarrow 3)-\beta$-Dglucuronopyranosyl (11), and 7-Hydroxy-6,7-dihydro-cis/trans- geraniate, 3-O- $\alpha$-L-arabinopyranosyl $(1 \rightarrow 6)$ - $\beta$-D-glucopyranosyl (12).

In recent reports, compounds 13-15, 18 and 19 have been reported to show potent $\alpha$-amylase inhibitory activity [14], and compounds 13, 15-19 were recently determined to be effective 
$\alpha$-glucosidase inhibitors by Nguyen et al., 2018 [17]. Of these, Walterolactone A (1a) and B (1b) $\beta$-D-glucopyranoside (13) was identified as a new compound in a previous study [14]. This study was the first to report its potent antioxidant activity; as such, Walterolactone A (1a) and B (1b) $\beta$-D-glucopyranoside (13), together with walterolactone A/B 6-O-gallate- $\beta$-D-glucopyranoside (9), which is a new compound investigated in this study, were determined as new effective antioxidants.

Table 2. Evaluation of the antioxidant activity of the isolated compounds.

\begin{tabular}{|c|c|c|c|}
\hline No. & Isolated compounds & DPPHFRS50 $(\mu \mathrm{g} / \mathrm{mL})$ & $\operatorname{Max}(\%)$ \\
\hline 1 & Umbelactone (new natural product) & - & - \\
\hline 2 & Walterolactone & - & _ \\
\hline 3 & Phenylalanine & - & - \\
\hline 4 & 2-methoxy-4-hydroxyphenol-1-O- $\beta$-D-glucopyranoside & $38.09^{\mathrm{b}}$ & $92^{\mathrm{a}}$ \\
\hline 5 & 1- $\beta$-D-glucopyranosyloxy-3,5-dimethoxy-4-hydroxybenzene & $58.11^{\mathrm{a}}$ & $100^{\mathrm{a}}$ \\
\hline 6 & 3,4-Dihydroxybenzoic acid & $16.77^{\mathrm{e}}$ & $95^{\mathrm{a}}$ \\
\hline 7 & 2-benzoyl myo-inositol (new natural product) & - & - \\
\hline 8 & 1-O-Benzoyl-myo-inositol (new natural product) & - & - \\
\hline 9 & $\begin{array}{l}\text { Walterolactone A/B 6-O-gallate- } \beta \text {-D-glucopyranoside } \\
\text { (new compound) }\end{array}$ & $10.9^{\mathrm{e}, \mathrm{f}}$ & $96^{\mathrm{a}}$ \\
\hline 10 & $\begin{array}{l}\text { Roseoside }(6 \mathrm{~S}, 9 \mathrm{~S}) \\
\left(3 R^{*} 6 R^{*}\right) \text {-tetrahydro-6-ethenyl-2,2,6-trimethyl-2H-pyran }\end{array}$ & - & - \\
\hline 11 & $\begin{array}{l}\text { 3-O- } \alpha \text {-L-arabinopyranosyl }(1 \rightarrow 3) \text { - } \beta \text {-D-glucuronopyranosyl } \\
\text { (new compound) }\end{array}$ & UD & $25^{b}$ \\
\hline 12 & $\begin{array}{l}\text { 7-Hydroxy-6,7-dihydro-cis/trans-geraniate, } 3 \text {-O- } \alpha \text {-L- } \\
\text { arabinopyranosyl }(1 \rightarrow 6)-\beta \text {-D-glucupyranosyl (new compound) }\end{array}$ & UD & $20^{\mathrm{b}}$ \\
\hline 13 & Walterolactone A (1a) and B (1b) $\beta$-D-glucopyranoside & $28^{c, d}$ & $98^{\mathrm{a}}$ \\
\hline 14 & Gallic acid & $9^{\mathrm{f}}$ & $97^{\text {a }}$ \\
\hline 15 & $(-)$-Gallocatechin & $30.73^{c}$ & $93^{\mathrm{a}}$ \\
\hline 16 & $\begin{array}{l}\text { 1-(4-hydroxyphenyl)-2,3-dihydroxypropan-1-one 3-O- } \beta \text {-D- } \\
\text { glucopyranoside/or Schweinfurthinol 9-O- } \beta \text {-D-glucopyranoside }\end{array}$ & - & - \\
\hline 17 & $\begin{array}{l}\text { Myo-inositol 1-O-3,3-dimethylacrylate/or } \\
\text { 1-O-(3-methyl)-butenoyl-myo-inositol }\end{array}$ & - & - \\
\hline 18 & Leonuriside & $27.47^{\mathrm{c}, \mathrm{d}}$ & $95^{\mathrm{a}}$ \\
\hline 19 & $(+)$-Catechin & $7.10^{\mathrm{f}}$ & $97^{\mathrm{a}}$ \\
\hline 20 & Methyl galloate & $9.4^{\mathrm{f}}$ & $96^{\mathrm{a}}$ \\
\hline 21 & $(-)$-Catechin & $11.5^{\mathrm{e}, \mathrm{f}}$ & $96^{\mathrm{a}}$ \\
\hline \multirow[t]{3}{*}{22} & $\begin{array}{l}\text { (3,5-dimethoxy-4-hydroxyphenol)-1-O- } \beta \text {-D-(6'-O-galloyl)- } \\
\text { glucopvranoside }\end{array}$ & $7.8^{\mathrm{f}}$ & $96^{\mathrm{a}}$ \\
\hline & $\alpha$-Tocopherol (commercial antioxidant) & $23^{d}$ & $99^{\text {a }}$ \\
\hline & CV (Coefficient of variation, $\%$ ) & 12.33842 & 7.156336 \\
\hline
\end{tabular}

The purified compounds were tested for their antioxidant activity at concentrations in the range of $0.5-250 \mu \mathrm{g} / \mathrm{mL}$. The results were presented as the means \pm SD of multiple tests $(n=3)$. The means of max inhibition and FRS50 with different letters in the same column were significantly different based on Duncan's multiple range test at alpha $=0.01$ (UD: unable to determine).

\subsection{Anti-Inflammation and Cytotoxicity of Euonymus laxiflorus Champ. Extract and its Major Compounds}

Nitric oxide (NO) has been suggested as a mediator of pro-inflammatory activity related to certain inflammatory disorders, including chronic hepatitis, pulmonary fibrosis, and rheumatoid arthritis. In this study, the crude extract (ELCTB) and its major identified compounds (1, 2, and 15) were evaluated for anti-NO activity with the use of LPS-stimulated RAW 264.7 cells. As shown in Figure 5a, Walterolactone A (1a) and B (1b) $\beta$-D-glucopyranoside (13) showed the most effective anti-inflammation properties and gallic acid (14) demonstrated acceptable activity with max inhibition and $\mathrm{IC}_{50}$ values of $100 \%, 1.3 \mu \mathrm{g} / \mathrm{mL}$ and 56\%, $145 \mu \mathrm{g} / \mathrm{mL}$, respectively, while (+)-Catechin (19) and the crude extract possessed weak activity with a max inhibition of 33.7\% and 6\%, respectively. Quercetin, a commercial anti-NO compound, was tested for comparison and showed max inhibition and $\mathrm{IC}_{50}$ values of $100 \%, 1.21 \mu \mathrm{g} / \mathrm{mL}$, respectively. The results indicated that Walterolactone A (1a) and B (1b) $\beta$-D-glucopyranoside (13) demonstrated promising activity which was equal to that of the positive control. Notably, Walterolactone A (1a) and B (1b) $\beta$-D-glucopyranoside (13) was investigated for the 
efficacy of its anti-NO activity for the first time in the current study and was found to be a new effective anti-NO compound. In the previous study, a total of 11 constituents were isolated and identified from the stems and leaves of Euonymus laxiflorus. Of these purified compounds, laxifolone A (a triterpene) displayed significant anti-NO effects [29].

The cytotoxicity of Euonymus laxiflorus Champ. extract and its major compounds were also examined using the same cell model based on LPS-stimulated RAW 264.7 cells. The cytotoxicity of the crude extract and its major identified compounds were tested using a large concentration range of $20-160 \mu \mathrm{g} / \mathrm{mL}$. The results (Figure $5 \mathrm{~b}$ ) showed that the major isolated compounds of ELCTB all slightly enhanced the growth of normal cells and that the ELCTB extract, as well as its major compounds (13, 14, and 19), had no toxicity to normal cells. In the previous study [3], The ELCTB extract was reported to show no toxic effects on a mouse model at a high dose of $300 \mathrm{mg} / \mathrm{kg}$ bw (body weight). The results of this study, as well as those of recently reported researches [3], confirmed that ELCTB was a natural and safe material with promising biomedical activities, including enzymic inhibition, hypoglycemic effects, and antidiabetic, antioxidant, and anti-NO activities.

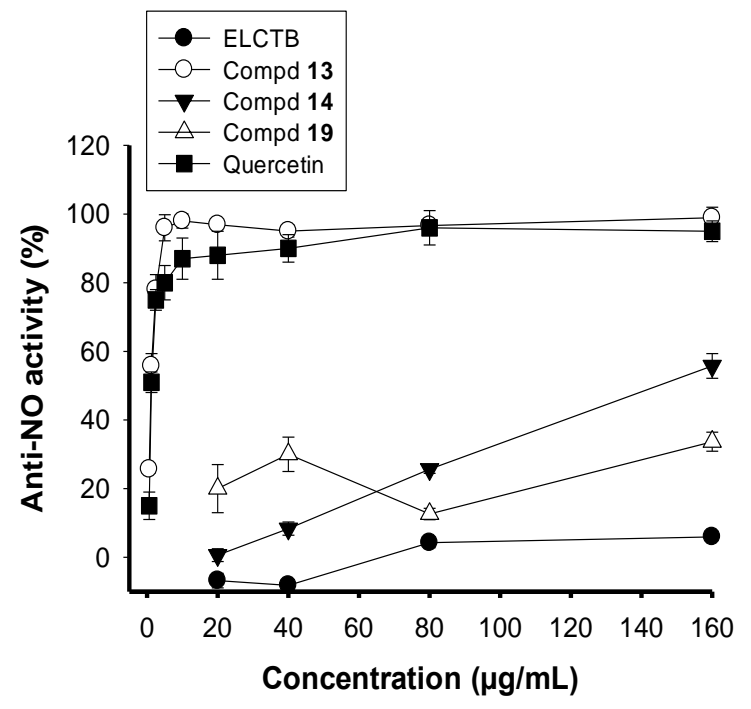

(a)

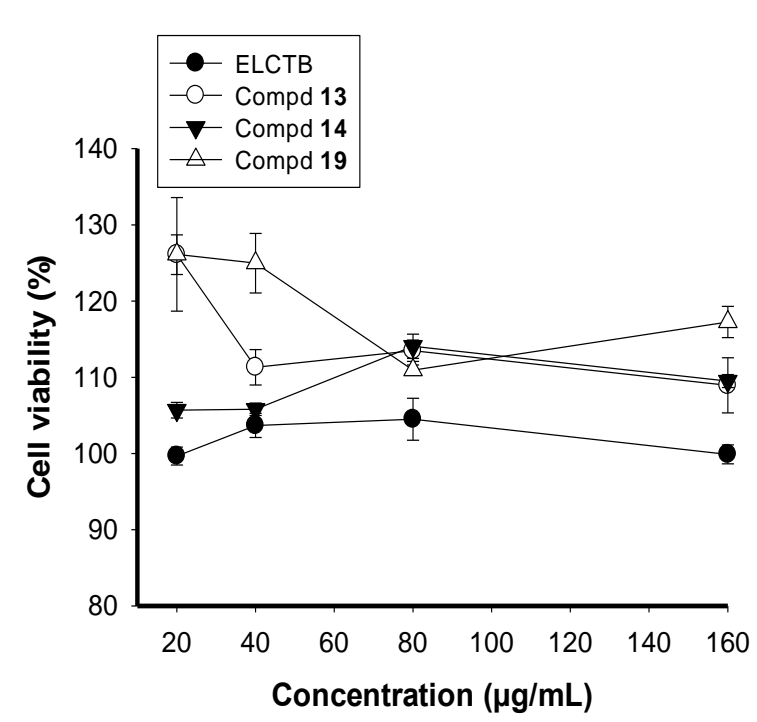

(b)

Figure 5. Anti-NO activity (a), and cytotoxicity (b) of Euonymus laxiflorus Champ. trunk bark (ELCTB) extract and its isolated compounds, including Walterolactone A (1a) and B (1b) $\beta$-D-glucopyranoside (13), gallic acid (14), and (+)-Catechin (19).

\section{Materials and Methods}

\subsection{Materials}

The ELCBT extract was obtained according to a previous study reported by Nguyen et al., 2017 [11]. 2-diphenyl-1-picrylhydrazyl (DPPH) and ODS gel were purchased from Sigma Chemical Co. (St. Louis City, MO, USA) and Merck Sigma Chemical Co. (St. Louis City, MO, USA), respectively. Reagents, other common chemicals, and solvents were available at the highest grade.

\subsection{Biological Activity Assays}

Free radical scavenging activity was determined through use of the DPPH radical scavenging activity assay described by Nguyen et al., 2018 [9] with minor modifications. One hundred and twenty microliters $(120 \mu \mathrm{L})$ of the samples (diluted with methanol at a concentration range of $0.5-250 \mu \mathrm{g} / \mathrm{mL}$ ) were mixed with $30 \mu \mathrm{L}$ of $0.75 \mathrm{mM}$ DPPH in methanol in a 96-well plate and then kept in the dark for 
$30 \mathrm{~min}$. The optical density of the mixtures at $517 \mathrm{~nm}\left(\mathrm{OD}_{517 \mathrm{~nm}}\right)$ was measured [30]. The following formula (1) was used to calculate the antioxidant activity:

$$
\text { Activity }(\%)=\left(\frac{A-B}{A}\right) \times 100 \%
$$

where, $A$ refers to the $\mathrm{OD}_{517 n m}$ of the blank sample (no antioxidants/samples in the mixture solution) and $B$ stands for the $\mathrm{OD}_{517 \mathrm{~nm}}$ of the sample solution at $30 \mathrm{~min}$ of incubation. The concentration of an antioxidant compound that can reduce $50 \%$ of the purple color of the DPPH solution under the assay conditions was defined as the FRS50 value [9]. $\alpha$-Tocopherol dissolved in $\mathrm{MeOH}$ was used as the positive control.

An anti-inflammation assay was also performed according to the methods described in detail by Nguyen et al., 2018 [9]. The tests were all repeated in triplicate and the differences between the mean values of the antioxidant and anti-NO activity $(p<0.01)$ were analyzed using Statistical Analysis Software (SAS-9.4, provided by SAS Institute Taiwan Ltd., Minsheng East Road, Section 2, Taipei, Taiwan 149-8).

\subsection{Purification Procedures and Identification of Active Compounds}

A total of $40 \mathrm{~g}$ of ELCTB extract were loaded onto a Diaion (Mitsubishi Chemical Co., Tokyo, Japan) column and primarily separated into five major fractions: ELCTB-1 (20.97 g), ELCTB-2 (9.12 g), ELCTB-3 (4.67 g), ELCTB-4 (1.46 g), and ELCTB-5 (1.63 g) using successive eluting with distilled water, $40 \% \mathrm{MeOH}, 70 \% \mathrm{MeOH}, 100 \% \mathrm{MeOH}$, and $100 \%$ ethyl acetate, respectively. ELCTB-2 $(4 \mathrm{~g})$ and ELCTB-3 (4 g) were sub-fractionated via the ODS column to obtain 10 sub-fractions (ELCTB.2.1-ELCTB.2.10) as well as 10 sub-fractions (ELCTB.3.1-ELCTB.3.10) eluted with gradient mobile phases of $0-100 \% \mathrm{MeOH}$ in $\mathrm{H}_{2} \mathrm{O}, v / v$ and $10-100 \% \mathrm{ACN}$ in $\mathrm{H}_{2} \mathrm{O}, v / v$, respectively. Of these, ELCTB.2.1, ELCTB.2.2, ELCTB.2.3, and ELCTB.3.3, which were eluted with distilled water, $\% \mathrm{MeOH}$, $10 \% \mathrm{MeOH}$, and $20 \% \mathrm{ACN}$, respectively, were further injected into preparative HPLC (a preparative Cosmosil 5C18-AR-II column equipped with $250 \times 20 \mathrm{~mm}$ i.d. and a UV detector (Nacalai Tesque, Inc., Kyoto, Japan) at 221 and $254 \mathrm{~nm}$ ), to obtain 12 compounds (1-12). Compounds 1-8 were eluted with $5 \% \mathrm{ACN}$, compound 11 was eluted with $9 \% \mathrm{ACN}$, and compounds $\mathbf{9}, \mathbf{1 0}$, and $\mathbf{1 2}$ were eluted with $23 \%$ $\mathrm{MeOH}$. The isolation process of the active compounds from the ELCTB extract are briefly summarized in Figure 1. The chemical structures of the isolated constituents were identified by analysis of their NMR data and a comparison with the reported compounds. The ${ }^{1} \mathrm{H}$ and ${ }^{13} \mathrm{C}-\mathrm{NMR}$ spectra and the 2D-NMR spectra, including NOESY, HMBC, HMQC, and COSY, were measured in $\mathrm{MeOH}-d_{4}$ on a Bruker AVX NMR spectrometer (Bruker, Karlsruhe, Germany), which operated at $600 \mathrm{MHz}$ for 1-12 h and $150 \mathrm{MHz}$ for ${ }^{13} \mathrm{C}$ spectra measurement, and the $\mathrm{MeOH}-d_{4}$ solvent peak was used as the internal standard $\left(\delta_{\mathrm{H}} 3.317, \delta_{\mathrm{C}} 49.1 \mathrm{ppm}\right)$.

\section{Conclusions}

A total of 12 phenolics (1-12) were newly isolated and identified from Euonymus laxiflorus. Of these, three constituents (9), (11), and (12) were identified as new compounds, while (1), (7), and (8) were identified as new natural products. These 12 compounds and the other 10 compounds (13-22) obtained from our previous work were evaluated for their antioxidant activity. Notably, 12 compounds $(\mathbf{4}-\mathbf{6}, \mathbf{9}, \mathbf{1 3}-\mathbf{1 5}, \mathbf{1 8}-\mathbf{2 2})$ displayed potent antioxidant activity (FRS50 $=7.8-58.11 \mu \mathrm{g} / \mathrm{mL})$ compared to $\alpha$-tocopherol (FRS50 $=23 \mu \mathrm{g} / \mathrm{mL}$ ). Among these, two constituents, (9) and (13), were determined to be new antioxidants. In the anti-NO activity tests, walterolactone A (1a) and B (1b) $\beta$-D-glucopyranoside (13) was found to have the most effective and comparable activity to that of quercetin, with max inhibition and $\mathrm{IC}_{50}$ values of $100 \%, 1.3 \mu \mathrm{g} / \mathrm{mL}$ and $100 \%, 1.21 \mu \mathrm{g} / \mathrm{mL}$, respectively, and this compound was reported to have anti-NO activity for the first time. The crude extract and its major compounds showed no cytotoxicity on normal cells. The results of the current study confirmed that ELCTB was a rich natural source of active phenolics that could be developed as a health food with 
promising antioxidant, anti-NO, and other beneficial biological activities. The results of this study also contributed to the enrichment of new natural products and the enrichment of novel compounds, as well as the novel biological activity of the constituents isolated from Euonymus laxiflorus.

Author Contributions: Conceptualization: V.B.N. and S.-L.W.; Methodology: V.B.N. and S.-L.W.; Software: V.B.N.; Validation: S.-L.W., V.B.N., and Y.-H.K.; Formal analysis: V.B.N., Y.-H.K. and S.-L.W.; Investigation: V.B.N.; Resources: V.B.N., A.D.N., and S.-L.W.; Data curation: V.B.N., Z.-H.L., C.T.D., T.N.T, and H.T.H.; Original draft: V.B.N.; Review and Editing: V.B.N. and S.-L.W.; Visualization: S.-L.W., Y.-H.K. and V.B.N.; Supervision: S.-L.W. and V.B.N.; Project administration: V.B.N., S.-L.W., A.-D.N., and Y.-H.K.

Acknowledgments: This work was supported in part by a grant from the Ministry of Science and Technology, Vietnam (MOST. NVQG-2018/19), the Ministry of Science and Technology, Taiwan (MOST 106-2320-B-032-001-MY3), the Ministry of Education, Taiwan (TKU 0657010), the Ministry of Science and Technology, Taiwan (MOST104-2320-B-077-006-MY3, MOST107-2320-B-077-003-MY3), and the Ministry of Health and Welfare, Taiwan (MM10601-0160, MM10701-0117).

Conflicts of Interest: The authors declare no conflict of interest.

\section{References}

1. Lobo, V.; Patil, A.; Phatak, A.; Chandra, N. Free radicals, antioxidants and functional foods: Impact on human health. Pharmacogn. Rev. 2010, 4, 118-126. [CrossRef] [PubMed]

2. Grice, P. Aristotle on the multiplicity of being. Pac. Philos. Q. 1988, 69, 175-200. [CrossRef]

3. Al-Jaber, N.A.; Awaad, A.S.; Moses, J. Review on some antioxidant plants growing in Arab world. J. Saudi Chem. Soc. 2011, 15, 293-307. [CrossRef]

4. Nguyen, Q.V.; Nguyen, N.H.; Wang, S.L.; Nguyen, V.B.; Nguyen, A.D. Free radical scavenging and antidiabetic activities of Euonymus laxiflorus Champ. extract. Res. Chem. Intermed. 2017, 43, 5615-5624. [CrossRef]

5. Nguyen, Q.V.; Nguyen, V.B.; Eun, J.B.; Wang, S.L.; Nguyen, D.H.; Tran, T.N.; Nguyen, A.D. Anti-oxidant and antidiabetic effect of some medicinal plants belong to Terminalia species collected in Dak Lak Province, Vietnam. Res. Chem. Intermed. 2016, 42, 5859-5871. [CrossRef]

6. Liang, T.W.; Tseng, S.C.; Wang, S.L. Production and characterization of antioxidant properties of exopolysaccharides from Paenibacillus. mucilaginosus TKU032. Mar. Drugs 2016, 14, 40. [CrossRef] [PubMed]

7. Wang, S.L.; Li, H.T.; Zhang, L.J.; Lin, Z.H.; Kuo, Y.H. Conversion of squid pen to homogentisic acid via Paenibacillus sp. TKU036 and the antioxidant and anti-inflammatory activities of homogentisic acid. Mar. Drugs 2016, 14, 183. [CrossRef]

8. Sila, A.; Bougatef, A. Antioxidant peptides from marine by-products: Isolation, identification and application in food systems. A review. J. Funct. Foods 2016, 21, 10-26. [CrossRef]

9. Nguyen, V.B.; Nguyen, T.H.; Doan, C.T.; Tran, T.N.; Nguyen, A.D.; Kuo, Y.-H.; Wang, S.-L. Production and bioactivity-guided isolation of antioxidants with $\alpha$-glucosidase inhibitory and anti-NO properties from marine chitinous materials. Molecules 2018, 23, 1124. [CrossRef]

10. Nguyen, Q.V. Antioxidant and anticancer activities of extracts and compounds isolated from Terminalia nigrovenulosa plant grown in Vietnam. Asian J. Biol. 2017, 3, 1-10. [CrossRef]

11. Nguyen, D.N.V.; Nguyen, T. An Overview of the Use of Plants and Animals in Traditional Medicine Systems in Viet Nam; Clark, L., Ed.; TRAFFIC Southeast. Asia, Greater Mekong Programme: Ha Noi, Viet Nam, 2008. Available online: http://www.trafficj.org/publication/08_medical_plants_Viet_Num.pdf (accessed on 23 December 2018).

12. Nguyen, V.B.; Nguyen, Q.V.; Nguyen, A.D.; Wang, S.L. Screening and evaluation of $\alpha$-glucosidase inhibitors from indigenous medicinal plants in Dak Lak Province, Vietnam. Res. Chem. Intermed. 2017, 43, 3599-3612. [CrossRef]

13. Nguyen, V.B.; Nguyen, Q.V.; Nguyen, A.D.; Wang, S.L. Porcine pancreatic $\alpha$-amylase inhibitors from Euonymus laxiflorus Champ. Res. Chem. Intermed. 2017, 43, 259-269. [CrossRef]

14. Nguyen, V.B.; Wang, S.L.; Nguyen, A.D.; Vo, T.P.K.; Zhang, L.J.; Nguyen, Q.V.; Kuo, Y.H. Isolation and identification of novel $\alpha$-amylase inhibitors from Euonymus laxiflorus Champ. Res. Chem. Intermed. 2018, 44, 1411-1424. [CrossRef] 
15. Nguyen, Q.V.; Wang, S.L.; Nguyen, A.D. In vitro a-glucosidase and a-amylase inhibition, and in vivo anti-hyperglycemic effects of Psidium littorale Raddi leaf extract. Res. Chem. Intermed. 2018, 44, 1745-1753. [CrossRef]

16. Nguyen, V.B.; Wang, S.-L.; Nhan, N.T.; Nguyen, T.H.; Nguyen, N.P.D.; Nghi, D.H.; Cuong, N.M. New records of potent in-vitro antidiabetic properties of dalbergia tonkinensis heartwood and the bioactivity-guided isolation of active compounds. Molecules 2018, 23, 1589. [CrossRef] [PubMed]

17. Nguyen, V.B.; Wang, S.-L.; Nguyen, T.H.; Nguyen, M.T.; Doan, C.T.; Tran, T.N.; Lin, Z.-H.; Nguyen, Q.V.; Kuo, Y.-H.; Nguyen, A.D. Novel Potent Hypoglycemic Compounds from Euonymus laxiflorus Champ. and their effect on reducing plasma glucose in an ICR mouse model. Molecules 2018, 23, 1928. [CrossRef]

18. Flora of China. Available online: http:/ / www.efloras.org/florataxon.aspx?flora_id=2\&taxon_id=200012808 (accessed on 10 May 2018).

19. Liu, L.M.; Cheng, S.F.; Shieh, P.C.; Lee, J.C.; Chen, J.J.; Ho, C.T.; Kuo, S.C.; Kuo, D.H; Huang, L.J.; Way, T.D. The methanol extract of Euonymus laxiflorus, Rubia lanceolata and Gardenia jasminoides inhibits xanthine oxidase and reduce serum uric acid level in rats. Food Chem. Toxicol. 2014, 70, 179-184. [CrossRef] [PubMed]

20. Goldring, W.P.D.; Mann, J.; Brockbank, P. A Synthesis of (S)-(-)-Umbelactone and related alpha, beta-Butenolides. Synlett 2010, 4, 547-550. [CrossRef]

21. Kim, K.H.; Shin, Y.J.; Choi, S.U.; Lee, K.R. New cytotoxic $\delta$-valerolactones from Cornus walteri. Bull. Korean Chem. Soc. 2011, 32, 2443-2445. [CrossRef]

22. Ip, N.Y.Y.; Ip, F.C.F.; Guo, S.; Ng, Y.P. Rhizoma arisaematis Extracts and Uses Thereof for Wound-Healing Effects. Patent WO2013/56514 A1, 2013.

23. Wang, J.; Di, Y.; Yang, X.; Li, S.; Wang, Y.; Hao, X. Hydroquinone diglycoside acyl esters from the stems of Glycosmis pentaphylla. Phytochemistry 2006, 67, 486-491. [CrossRef]

24. Shao, J.H.; Chen, J.; Zhao, C.C.; Shen, J.; Liu, W.Y.; Gu, W.Y.; Li, K.H. Insecticidal and $\alpha$-glucosidase inhibitory activities of chemical constituents from Viburnum fordiae Hance. Nat. Prod. Res. 2018, 27, 1-6. [CrossRef] [PubMed]

25. Khallouki, F.; Haubner, R.; Ricarte, I.; Erben, G.; Klika, K.; Ulrich, C.M.; Owen, R.W. Identification of polyphenolic compounds in the flesh of Argan (Morocco) fruits. Food Chem. 2015, 179, 191-198. [CrossRef] [PubMed]

26. Chung, S.K.; Chang, Y.T. Synthesis of all possible regioisomers of myo-Inositol pentakisphosphate. Bioorg. Med. Chem. Lett. 1996, 6, 2039-2042. [CrossRef]

27. Amparo, Z.; Roberto, F.d.l.P.; Manuel, M.L.; Soledad, P. Novel highly regioselective O-alkylation and O-acylation of myo-inositol. J. Org. Chem. 1991, 56, 444-447.

28. Yamano, Y.; Ito, M. Synthesis of optically active vomifoliol and roseoside stereoisomers. Chem. Pharm. Bull. 2005, 53, 541-546. [CrossRef] [PubMed]

29. Kuo, Y.H.; Huang, H.C.; Chiou, W.F.; Shi, L.S.; Wu, T.S.; Wu, Y.C. A Novel NO-production-inhibiting triterpene and cytotoxicity of known alkaloids from Euonymus laxiflorus. J. Nat. Prod. 2003, 66, 554-557. [CrossRef] [PubMed]

30. Liang, T.W.; Chen, W.T.; Lin, Z.H.; Kuo, Y.H.; Nguyen, A.D.; Pan, P.S.; Wang, S.L. An amphiprotic novel chitosanase from Bacillus mycoides and its application in the production of chitooligomers with their antioxidant and anti-inflammatory evaluation. Int. J. Mol. Sci. 2016, 17, 1302. [CrossRef] [PubMed]

Sample Availability: Samples are not available from the authors. 